\title{
Editorial
}

\section{Bid-ding for mercy: twisted killer in action}

\author{
A Egle $^{\star, 1}$, D Asslaber ${ }^{1}$, A Villunger ${ }^{2}$ and J Pinon-Hofbauer ${ }^{1}$ \\ Cell Death and Differentiation (2013) 20, 847-849; doi:10.1038/cdd.2013.40
}

By the time Arnold Schwarzenegger utters the now famous words 'I'll be back', as he stares through his shades at the front desk of a soon to be defunct police station, we already know that his character in 'Terminator' is a relentless killing machine, programmed to eliminate his target. When he comes back in T2, he still has the habit of being an efficient killer, but now his main role is that of a protector. While this example is a bit less sophisticated than an allegory from Roman mythology (two-face Janus seemed a bit overused), it is still a valid example that a killer can have different effects depending on the context of the program he is put in.

In this issue of Cell Death and Differentiation, Biswas et al. ${ }^{1}$ point out a similarly ambivalent role of the pro-apoptotic $\mathrm{BH} 3-$ only protein Bid in tumorigenesis. This serves as an example that even in the world of the Bcl-2 family, you can't be certain who the villains are.

Even before its function was clear, $\mathrm{Bcl}-2$ was implicated as a villain in tumorigenesis in lymphoma. After it became evident that $\mathrm{Bcl}-2$ inhibited cell death, ${ }^{2}$ it turned out that it was a lousy oncogene on its own. ${ }^{3}$ However, in combination with an oncogene driving proliferation (such as Myc), the effects were strong. ${ }^{4}$ This phenomenon may be due to an inhibitory function of $\mathrm{Bcl}-2$ in cell cycle entry control and the need to override it (for a review see ${ }^{5}$ ). Since we have seen the discovery of a large number of family relatives, it has become clear that all the anti-apoptotic family members tested were able to accelerate Myc-induced lymphoma. ${ }^{6}$ So far, so easy. Villains nailed! So who are the good guys? The prime candidates were Bax/Bak or the BH3-only inducers of cell death. And indeed, a role as tumor suppressors of spontaneous tumorigenesis (for $\mathrm{Bid}^{7}$ ) and in Myc-induced $\mathrm{B}$ cell lymphomagenesis (for $\mathrm{Bim}^{8}$ ) were reported. Again, the spontaneous effect of loss of $\mathrm{BH} 3$-only proteins was a weak stimulus for tumorigenesis, with low incidences and long latencies for the myeloid tumors observed in Bid-deficient mice. Again, the effect in the context of a driver was strong, as could be seen with the loss of Bim in Myc-transgenic mice. Since these two observations, many of the BH3-only genes have shown varying degrees of tumor suppressing potential in the context of Myc-transgenic lymphomagenesis (e.g. Bim, Puma, Bad, Bmf ${ }^{8-10}$ ). Remarkably, the notable exception to this rule appeared to be $\mathrm{Bid},{ }^{11}$ an interesting observation given that loss of Bid seemed to have the strongest effect on spontaneous tumor development. ${ }^{7}$ But overall, again - so far so good! The villains and the good guys had been separated. And this is where we think of Arnie again! Some of the good guys seem to have a night-job, happy to join the dark side, at least once in a while. When Puma-deficient mice were subjected to an irradiation (IR) carcinogenesis protocol that reliably produces thymic lymphoma in wild-type mice, it turned out, surprisingly, that loss of Puma completely abrogated lymphoma formation. ${ }^{12,13}$ The two observations reported suggested that Puma-induced cell death was important for tumor formation in this context, and that repeated replicative stress in the hematopoietic stem/progenitor cell (HSPC) compartment drove oncogenesis. In this setting, loss of Puma was limiting this replicative stress by protecting HSPCs from death, presumably removing the impetus for replication to fill the emptied niches. Of note, similar observations have since been made in carcinogen (i.e. DEN)-driven liver cancer, assigning broader relevance to these initial observations. ${ }^{14}$ Now, Zinkel et al. present a similar case: ${ }^{1}$ loss of Bid in the context of thymic lymphomagenesis, generated by loss of ATM rather than IR-driven DNA damage, led to a significant delay in tumor formation. This time, liver cancer led the way. Loss of Bid delayed DEN-driven formation of microfoci, suggesting a role of Bid in promoting hepatocarcinogenesis. ${ }^{15}$ The authors found that despite an observed protection from cell death, livers in Bid-deficient mice showed significantly reduced proliferation. The arguments regarding the mechanism by which tumor suppression is achieved in the context of ATM-loss, however, are different. ${ }^{1}$ The authors and others have previously shown that Bid was involved in the DNA damage response. ${ }^{16,17}$ This role of Bid has been disputed and was the subject of controversial debate ${ }^{18-20}$ that we will not be able to resolve in this editorial. However the mechanics may be, the authors put forward a model wherein an initial disarmament of a Bid-dependent checkpoint results in the increased proliferation of highly DNA-damaged cells and the subsequent death of this vulnerable population. The overall effect is the deletion of cells with potential oncogenic lesions leading to the delay in tumor formation. This is supported by the increased cell death vulnerability of early thymocytes (DN3 for the aficionados) that are the subject of RAG-driven

\footnotetext{
${ }^{1}$ Department of Internal Medicine III with Hematology, Medical Oncology, Hemostaseology, Infectious Diseases, Rheumatology, Oncologic Center, Laboratory for Immunological and Cancer Research, Paracelsus Medical University Salzburg, Salzburg, Austria and ${ }^{2}$ Division of Developmental Immunology, Biocenter, Medical University of Innsbruck, Innsbruck, Austria

${ }^{*}$ Corresponding author: A Egle, Department of Internal Medicine III with Hematology, Medical Oncology, Hemostaseology, Infectious Diseases, Rheumatology, Oncologic Center, Laboratory for Immunological and Cancer Research, Paracelsus Medical University, Muellnerhauptstrasse 48, Salzburg, Austria. Tel: +43 6624482 3407; Fax: +43 6624482 3468; E-mail: a.egle@ salk.at
} 


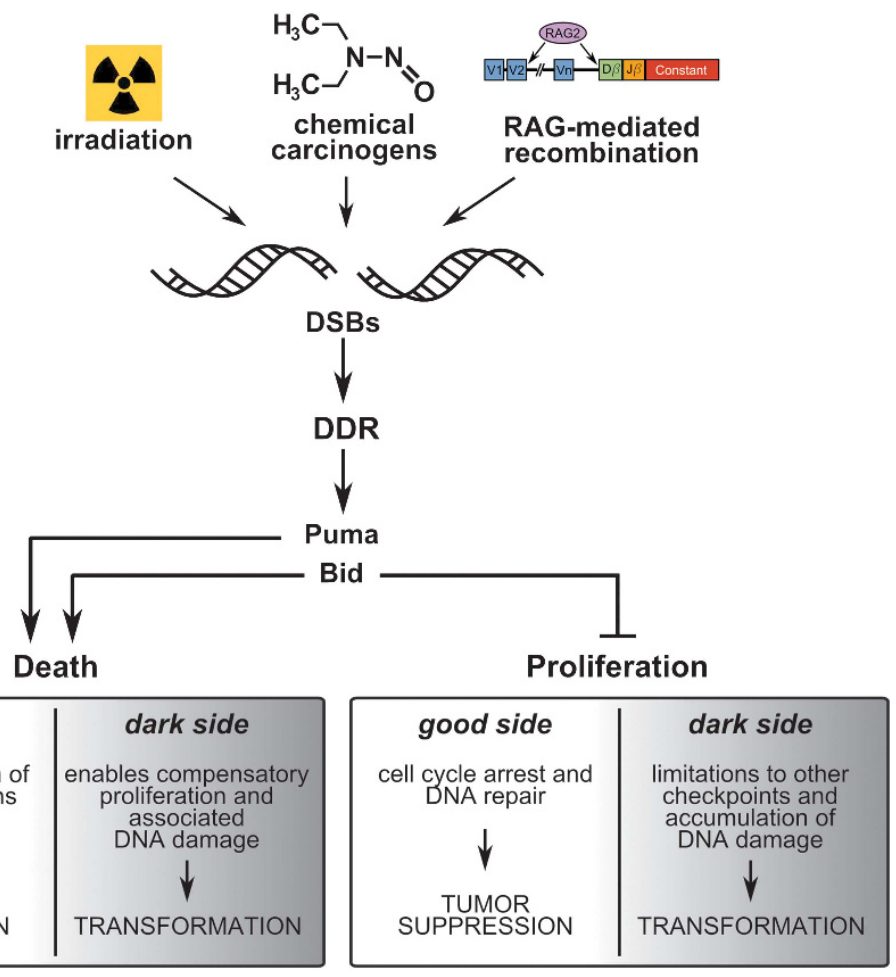

Figure 1 DNA damage engages (among other effectors) BH3-only proteins Bid and Puma. The cell death function of both proteins can act to suppress or aid tumor formation depending on the context. A cell cycle activity of Bid may also have those two sides and interfere favorably or unfavorably with other checkpoints. Please refer to text for further explanation

transformation in the absence of an ATM-dependent checkpoint control in $\mathrm{Atm}^{-1-} \mathrm{Bid}^{-1-}$ mice. This is clearly a fascinating and unexpected explanation as it highlights key differences to the IR-driven lymphoma model. While the authors can show that HSPC numbers and replating capacity is essentially unchanged by Atm/Bid loss in steady state and at early time points after irradiation, it would be interesting to know the state of cell cycling in these cells, as impaired proliferation due to Bid-deficiency was offered as one possible explanation delaying disease in the HCC model. ${ }^{15}$ Indeed, proliferation induced to compensate for loss of cells due to the DEN effect was described as a major driver of carcinogenesis in this model system, and this has some interesting parallels to the findings from IR-induced thymic lymphoma (mentioned above in the context of Puma-deficient mice). Thus, all the models that have uncovered tumor-promoting effects of $\mathrm{BH}$ only proteins rely on some highly proliferative cell population. In this respect, it is very interesting to note that in the study presented here, Atm/Bid doubly-deficient DN3 cells have a higher basal turnover (as commented in the paper), but also display the strongest growth arrest upon irradiation (See Fig $2 \mathrm{c}$, d in Biswas et $\mathrm{al}^{1}$ ). It remains open which checkpoint mechanism arrests and/or subsequently kills these cells or whether these damaged cells die due to mitotic catastrophe (for a graphic rendition see Figure 1). Furthermore, although the data clearly show that in the case of Bid-deficiency it does not seem to be a protection from cell death in the stem cell compartment that could be responsible for the surprising effect, a growth arrest of stem cells in response to DNA damage may go unnoticed by the assays used in the paper, but may substantially change the quality of DNA repair in that compartment.

Based on the model put forward here, some earlier controversy on the role of Bid in DNA-damage induced apoptosis might be reconciled, as the data presented confirm the lack of protection of HSCP and early lymphocytes to IR-induced death by loss of Bid. In DN3 cells, however, the absence of Bid may lead to enhanced proliferation that can compensate for the loss of these cells usually observed in the absence of ATM, but at the same time renders them highly vulnerable to cell death. We don't know if this is only observed upon DNA damage or also other types of stress. Taken together with the data from liver cancer, the neglected role of Bcl-2 family members in directly or indirectly controlling cell cycle may hold some of the keys to their complex role in tumorigenesis.

Finally, and we think worth mentioning, there seems to be a highly relevant moment of tissue and even differentiation stage specificity regarding the role of $\mathrm{BH} 3$-only proteins in lymphomagenesis (also seen in our previous work ${ }^{8}$ ). An interdependence of checkpoints enforced during the clonal evolution of the immune repertoire and of DNA damage responses seems to create very specific situations where the BH3-only proteins contribute to the 'carefully regulated' balance between life and death in the hematopoietic system, as the authors put it in their final paragraph.

Contemplating how this paper points to a villainous side of Bid, previously suggested to act as a beneficial tumor suppressor, we have to admire the cunning career feat 
accomplished by Arnold Schwarzenegger to turn a mindless killing machine into a likeable character whose demise towards the end of the first sequel leaves the viewer with some regret. The biologic reality is, however, more complex than such Hollywood fiction. Indeed as is the case with all intriguing observations, we are left with more questions than answers - but have a read for yourselves.

Acknowledgements. Research in the Egle group is supported by Austrian FWF grants P19481-B12 and L488-B13, as well as by Paracelsus Medical University FFF grants E-11/14/070-EGP and E-11/13/063-EGL.

1. Biswas $S$ et al. Cell Death Differ 2013; 20: 869-877.

2. Vaux DL, Cory S, Adams JM. Nature 1988; 335: 440-442.

3. Mcdonnell TJ, Deane N, Platt FM et al. Cell 1989; 57: 79-88.
4. Strasser A, Harris AW, Bath ML, Cory S. Nature 1990; 348: 331-333.

5. Cory S, Huang DCS, Adams JM. Oncogene 2003; 22: 8590-8607.

6. Beverly LJ, Varmus HE. M Oncogene 2009; 28: 1274-1279.

7. Zinkel SS, Ong CC, Ferguson DO et al. Genes Dev 2003; 17: 229-239.

8. Egle A, Harris AW, Bouillet P, Cory S. Proc Natl Acad Sci USA 2004; 101: 6164-6169.

9. Frenzel A, Labi V, Chmelewskij W et al. Blood 2010; 115: 995-1005.

10. Michalak EM, Jansen ES, Happo L et al. Cell Death Differ 2009; 16: 684-696.

11. Manzl C, Peintner L, Krumschnabel G et al. Cell Death Differ 2012; 19: 1722-1732.

12. Labi V, Erlacher M, Krumschnabel G et al. Genes Dev 2010; 24: 1602-1607.

13. Michalak EM et al. Genes Dev 2010; 24: 1608-1613.

14. Qiu W et al. Hepatology 2011; 54: 1249-1258.

15. Bai L, Ni HM, Chen XY, DiFrancesca D, Yin XM. Am J Pathol 2005; 166: 1523-1532.

16. Kamer I et al. Cell 2005; 122: 593-603.

17. Zinkel SS, Hurov KE, Ong C, Abtahl FM, Gross A, Korsmeyer SJ. Cell 2005; 122 : 579-591.

18. Kaufmann T et al. Cell 2007; 130: 10-11.

19. Kaufmann T et al. Cell 2007; 129: 423-433

20. Zinkel SS, Hurov KE, Gross A. Cell 2007; 130: 9-10. 